\title{
28 Research Square \\ Productive and Reproductive Aspects in Dairy Cows Raised with and Without Access to Pasture in Southern Brazil
}

Rodrigo Schallenberger Gonçalves

Universidade Federal do Rio Grande do Sul

Fábio de Souza Guagnini

Autonomous Veterinary

Daniel Storck

Autonomus Vetrerinary

Mariana de Matos Brose

Universidade Federal do Rio Grande do Sul

Laura Victoria Quishpe Contreras

Universidade Federal do Rio Grande do Sul

Félix Hilário Diaz Gonzalez

Universidade Federal do Rio Grande do Sul

André Gustavo Cabrera Dalto ( $\nabla$ andre.dalto@ufrgs.br)

Universidade Federal do Rio Grande do Sul https://orcid.org/0000-0002-6983-659X

\section{Research Article}

Keywords: Dairy cows, Uterine diseases, Animal production, Metabolic parameters

Posted Date: July 13th, 2021

DOl: https://doi.org/10.21203/rs.3.rs-669879/v1

License: (9) (i) This work is licensed under a Creative Commons Attribution 4.0 International License.

Read Full License 


\section{Abstract}

Since productive performance in dairy cows is directly linked to the manner in which cows are raised, the breeding system can have a direct influence on the parameters of a farm. Unlike the main European and North American countries, in southern Brazil the use of confinement systems with access to pasture is widespread. Grazing cows are believed to be less stressed from the metabolic point of view. This study was conducted on nine commercial dairy farms located in the Serra Gaúcha, Rio Grande do Sul, Brazil, from September 2016 to November 2017. A total of 393 Holstein dairy cows were included immediately after birth. The dairy farms had an average of 45 lactating cows and were milked twice a day with an average milk production in 305 days of 9,500 kg / cow for the confinement system with access to pasture and $10,700 \mathrm{~kg} /$ cow for the confined system. The confinement system with access to pasture (CAP) was composed of five properties and was characterized by access to rotating pasture, while the confinement system without access to pasture (CNP) was composed of four properties. The study diagnosed uterine diseases, metabolic diseases and their correlations, and assessed the conception rate in the first service of the herds. Animals with access to pasture had generally lower production rates than animals reared in confinement, which suggests that the model with access to pasture used in the extreme south of the country can result in deleterious effects on animal production.

\section{Introduction}

Cows under good management conditions produce more milk, have better reproductive rates, become less ill and thus remain longer in the herd. On the other hand, stressed animals have less immunity, are difficult to handle and tend to consume less food, and since all these factors interfere with productivity, the longevity of such animals within the system can be affected as a consequence (Leblanc et al. 2006; Ingvartsen and Moyes 2015). The comparison of productive systems with access to pasture or in feedlot conditions has been the subject of numerous discussions on animal welfare (Chilibroste et al. 2007; Bond et al. 2012; Nascimento et al. 2013).

Nowadays in society, there is a great concern over animal welfare, which is reflected in the choice of food, that is, the consumer market increasingly seeks products that come from production systems that respect the standards of animal welfare (Nascimento et al. 2013). Consequently, pasture-based milk production systems have gained interest over the past decade due to their economic, environmental and animal welfare advantages (Chilibroste et al. 2007). Access to pasture is an important factor for the behavior and well-being of dairy cattle (Bond et al. 2012).

From the same point of view, the availability of area and the climate in southern Brazil make pastureraising animals quite viable. Due to its lower behavioral restriction, such a system potentially has advantages for animal welfare, provided that appropriate sanitary management and control practices are used and in place. The final balance between challenges and advantages for dairy farming in southern Brazil, which ultimately determines the quality of life of animals, is still greatly unknown due to the scarcity of publications in this area (Bond et al. 2012). 
Studies related to this topic are scarce and generally compare different regions and different times or between systems that are not used in our region. The objectives of this study were therefore to compare systems of animal production using either confined animals or confined animals with access to pasture, in relation to parameters related to productivity and reproduction.

\section{Materials And Methods}

This observational study was conducted on nine commercial dairy farms located in the Serra Gaúcha region, Rio Grande do Sul, southern Brazil, from September 2016 to November 2017. A total of 393 Holstein dairy cows were included in this study immediately after calving (126 primiparous and 267 multiparous). Of these, 203 animals were managed under a confined production system with access to pasture, and 190 animals were managed in a confined production system without pasture access. Dairy farms in this study had an average of 45 lactating cows and were milked twice daily with an average milk production in 305 days of $9,500 \mathrm{~kg} /$ cow in the confined with access to pasture (CAP) group, and 10,700 $\mathrm{kg} / \mathrm{cow}$ in the confined system with no pasture (CNP) group. The total diet for postpartum cows was calculated to meet or exceed the requirements of dairy cows according to the guidelines established by the NRC (2001). Weekly until the sixth postpartum week, cows were classified for body condition score (Edmonson et al. 1989) and rectal temperature (RT) was recorded. Animals with a gestation duration of less than 265 days and which underwent a cesarean section or any other surgical procedure at the time of delivery were excluded from the study.

The CAP group was composed of five properties and was characterized by its access for around six hours a day to rotating pasture of oats and ryegrass (in the period between May to November) and tifton 85 , Sudan grass and millet (in the period from December to April). Water was available ad libitum. In the remaining 18 hours, the cows were housed in free stalls with available food (fully mixed feed) and water or were being milked. In the CNP system, which was composed of four properties, cows had access to water and food ad libitum and the feed was completely mixed.

A total of four veterinarians were involved in this study. To standardize the reporting of clinical procedures and findings, all participating veterinarians received standard instructions, material and documentation at the beginning of the study. Various validations of procedures and classification of results were carried out throughout the study. All participating herds were within a $60 \mathrm{~km}$ radius and therefore shared similar climatic conditions.

\section{Statistical analysis}

Data were recorded onto a field spreadsheet and entered into the Microsoft Excel program. Later a database was created, and these data were exported to the statistical packages Epi Info 7.2, BioEstat 5.3 and SPSS 20.0.

Continuous variables with normal distribution were expressed as mean \pm standard deviation and categorical variables as frequencies and percentages. The cow was the experimental unit and considered 
a random effect. Residues were assessed for normality and homoscedasticity. The normality of the data was verified using the Shapiro-Wilk test. $P$ values $\leq 0.05$ were considered to be significant differences between the data found. In addition, $P$ values $\leq 0.1$ were considered as trends. Contrasts have been written to describe relationships of relevant interest.

The results were analyzed using the analysis of variance test (ANOVA) to determine the effect of some variables, such as: number of calving, rectal temperature, production system, considering location as a random effect, in addition to the analysis of effects fixed in relation to biochemical indicators of metabolism and uterine health. Pearson's Chi-square test or Fischer's exact test were used for comparisons of the occurrence of the postpartum diseases assessed and the conception rates for categorical variables. Additionally, linear and logistic regression models were built to determine the effect of the dependent variable on the other indicators, which can be continuous or categorical.

\section{Results}

Body condition score (BCS) differed between cows confined (CNP) and those with access to pasture (CAP) from calving to the sixth week postpartum $(p<0.01)$. CAP animals had a higher BCS in addition to losing more BCS from delivery until the sixth week, as shown in Fig. 1.

When comparing CNP and CAP animals, the beta-hydroxybutyrate concentration (BHB) average in the first week was not significantly different $(p=0.51)$, in the second week it was statistically significant $(p<$ 0.05), and CNP cows had lower a mean of BHB (1.15 mmol / L) compared to the CAP group (1.33 mmol / $\mathrm{L})$. In the third week a tendency was observed in animals under the CAP system having a greater BHB ( $p$ $=0.088)$, as shown in Fig. 2 .

There were no differences in cholesterol over the first two weeks postpartum, but in the third week animals from the CNP group had higher levels of cholesterol $(p<0.01)$. Total calcium showed difference in the first week $(p<0.05)$ between the CNP group $(7.6 \mathrm{mg} / \mathrm{dL})$ and the CAP group $(6.9 \mathrm{mg} / \mathrm{dL})$, not differing in the second and third week, as shown in Fig. 3. Albumin and AST were similar between the CNP group and CAP group during the first three weeks postpartum.

The average rectal temperature in the first three postpartum weeks was higher for CAP animals in comparison to healthy cows with the presence of uterine disease. These averages were also higher for patients during all weeks $(p<0.01)$, as shown in Fig. 4.

The occurrence of dystocia was not affected within the same production system between farms, however in the CAP group, animals showed an overall higher occurrence of dystocia. However, there were no differences between farms in the same system and between systems, in regard to the occurrence of clinical and subclinical diseases. Primiparous CAP animals had a higher occurrence of dystocia compared to primiparous CNP animals $(\mathrm{OR}=2.841 ; \mathrm{p}=0.012)$, and multiparous CNP animals $(\mathrm{OR}=$ 4.054; $p<0.001)$ had a trend when compared to multiparous CAP animals $(O R=1.786 ; p=0.075)$. In terms of subclinical endometritis in the sixth week, primiparous CAP cows had a higher occurrence than 
multiparous CNP $(O R=2.013 ; p=0.05)$ and multiparous CAP cows $(O R=2.824 ; p=0.004)$. Still, multiparous CAP animals had a higher incidence of dystocia compared to multiparous CNP animals (OR $=2.270 ; p=0.012$.

Regarding the presence of corpus luteum and follicles in the ovaries, there was no statistically significant difference between production systems, only a tendency for confined animals to have more active ovaries in the fourth week $(O R=1.448 ; p=0.092)$. In the analysis between farms and between systems, no differences were observed in terms of mortality and disposal rates.

Production system influenced the conception rate when comparing primiparous CNP animals with primiparous CAP animals, as shown in Fig. 5, with no differences between farms in the same production system.

\section{Discussion}

Our study showed that confined cows with access to pasture (CAP) had an average BCS at calving of 3.67, while confined cows (CNP) had an average BCS at calving of 3.00, with an average loss of BCS during the six weeks postpartum of 0.62 and 0.40 points for CAP and CNP groups, respectively. These results show that confined cows have better BCS, as previous studies suggest that cows should give birth at a BCS of 2.75 to 3.0, and not lose more than 0.5 of a BCS unit between calving and delivery (Overton and Waldron 2004). High levels of BCS before delivery, as well as large losses in postpartum body condition have been associated with displacement of the abomasum, ketosis and other metabolic-related diseases, decreased fertility and increased disposal rates (Duffield 2000). CAP cows had a body condition score at calving higher than CNP cows, in addition, they presented a greater loss of body condition over the six weeks postpartum. Similar to our results, researchers in Sweden showed that loss of body condition between 1 and 4 weeks after delivery tended to be related to the initial body condition ( $O^{\prime} \mathrm{Hara}$ et al. 2016). This agrees with another study which compared cows with or without pasture access (Astessiano et al. 2015), in that semi-confined cows lost more BCS than confined cows.

When comparing production systems, we found higher BHB averages in the second and third weeks postpartum for the CAP cows, a result that is in line with the BCS data of our study, as cows which show greater loss in BCS have a higher negative energy balance (NEB), reflecting an increase in BHB and a reduction in dry matter intake (Bell 1995; Horst et al. 1997). In this sense, there is a probable link between metabolic changes in peripartum in the dairy cow and immunosuppression (Ingvartsen and Moyes 2015).

Another interesting finding in our study when comparing production systems was that CAP animals had lower serum cholesterol concentrations in the first two weeks postpartum compared to CNP animals and had lower concentrations in the third week. A possible explanation for this result is that diseases associated with inflammation lower cholesterol, preventing the flow of cholesterol from cells (Vogel et al. 2011) and also that low concentrations of cholesterol in the first weeks after postpartum are also associated with higher BCS (Van Den Top et al. 2005). However, much of the variation in cholesterol can be explained by the consumption of dry matter in such a way that a lower consumption of food leads to 
lower levels of cholesterol, higher values of postpartum cholesterol are indicative of a lower degree of mobilization of the adipose tissue (Guretzky et al. 2006).

In terms of dystocia, in a study evaluating 450 births in the southern United States, $73.0 \%$ were classified as normal and $27.0 \%$ resulting in dystocia (Benzaquen et al. 2007), numbers very close to those found in our study, which was $21.6 \%$ resulting in dystocia, and well above the $5 \%$ found in Portugal (Koch 2013 ). In our study, the frequency of dystocia was significantly affected by the production system, contrary to previous studies that mention that access to pasture reduces dystocia (Popescu et al. 2013). In addition, Gustafson (1993) and Mee (2004) claim that the prevalence of dystocia can be increased by lack of exercise. Bendixen et al. (1986) showed that pasture cattle have a reduced incidence of dystocia. However, this higher frequency of dystocia may not be entirely true because tie-stall / pasture systems were being compared, whereas in our study we compared free-stall / pasture.

The reference range for bovine body temperature has been reported as $38.6 \pm 0.5^{\circ} \mathrm{C}$ (Andersson and Jónasson 1993); however, the limit above which a cow's postpartum RT is considered febrile varies considerably. Metritis and PR studies used RT thresholds $>39.5^{\circ} \mathrm{C}$ (Drillich et al. 2001, Sheldon et al. 2006) and $39.7^{\circ} \mathrm{C}$ (Sheldon et al. 2004). However, in monitoring programs, RT has diverged between primiparous cows $\left(39.4^{\circ} \mathrm{C}\right.$ ) and multiparous cows $\left(39.7^{\circ} \mathrm{C}\right)$ (Kristula et al. 2001). In our study differences were found between rectal temperature and the production system (CAP having higher RT than CNP), differences between healthy and sick animals (sick animals having higher RT then healthy animals), differences between cows that presented ovarian structures (lower RT, greater chance of presenting structures) and finally, the time of year also had an influence on RT (RT higher in the hot season in comparison to the cold season). This difference in the production system probably occurred because CAP cows tended to have more clinical diseases compared to CNP cows. Regarding the temperature in relation to uterine diseases, our findings were similar to those found by Suthar et al. (2012) who found RT values $0.8^{\circ} \mathrm{C}$ higher in animals with metritis and the differences between winter and summer in RT are similar to what the same study mentions. The normal RT of dairy cattle in the immediate postpartum period, during the hot summer months, is potentially higher than normal.

In our approach, the number of cows with clinical endometritis did not differ between production systems, which is at odds with the findings by Bruun et al. (2002), who suggest that uterine disorders were lower in herds with access to pasture. The possibility of animals exercising in the free-stall even if they do not have access to pasture may be a factor for there to be no differences in our study, or even the duration that cows had access to pasture in our study is reduced to bring some benefit in muscle strengthening.

In our study, we found a tendency in the fourth week for CNP animals to have more active ovaries compared to CAP animals, findings similar to those reported by Astessiano et al. (2015), who stated that cows confined with access to pasture have a more pronounced negative energy balance, negatively impacting the reproductive function and the return to cyclicality, contradicting the majority of research comparing cows on pasture with confined. In another study comparing ovulation in cows, animals without ovulation had lower BCS than normal ones (Giuliodori et al. 2011). In contrast to the presented 
results, in our study no difference was observed in conception rate when comparing multiparous and primiparous CAP animals, with significant differences when comparing primiparous and multiparous CNP animals or when comparing primiparous CNP and primiparous CAP, showing that primiparous CNP animals had better reproductive performance compared to primiparous CAP animals. The possible explanation for these results is that primiparous CAP animals are the ones with the most accentuated negative energy balance (NEB). Butler (2000) explained that the NEB is related to the lower capacity of energy consumption, the higher the NEB (time and intensity), the worse the reproductive performance at the beginning of lactation.

No differences in the rate of disposal and mortality between production systems were observed, contrary to previous studies which showed lower mortality in herds with access to pasture (Alvâsen et al. 2012), a difference that can be explained by the lower number of animals utilized in our study. Due to the smaller size of animals on the properties, more assistance can be given to the animals and they tend to discard fewer cows due to little replacement or even by the increase in the number of animals in the herd. The proportion of dead cows may be a consequence of socio-psychological differences between countries and regions in terms of practices around euthanasia and death (Boulton et al. 2017).

The results of our study demonstrated that animals raised in a confinement system with access to pasture (CAP) had worse productive performance for some of the analyzed parameters when compared with most studies which evaluated animals with and without access to pasture (Madoz et al. 2013; Popescu et al 2013). These differences may be explained by geographical location, as many studies were carried out in temperate and subarctic regions, where even in the summer the ambient temperature does not reach the high levels observed in Brazil, and where the production systems differ with regard to management. The only work that is in agreement with ours was carried out in Uruguay where the production systems and climate are comparable (Astessiano et al. 2015). Therefore, minimizing the harmful effects of the environment on animals in countries with tropical and subtropical climates must be a constant consideration (Leme et al. 2005).

As the cows in this study are high-yielding animals, it is necessary to reevaluate the management of the confinement system with access to pasture if it meets the needs of animals for comfort and productivity. In view of the contradictory results in relation to previous studies, we have further analyzed the effect of production management in the same region (differing only in breed), and it was found that animals which had access to pasture and apparently a more sustainable and comfortable system, presented lower performance indexes than animals raised in confinement.

\section{Declarations}

\section{Funding}

The National Council for Scientific and Technological Development (CNPQ) of Brazil was responsible for funding this research. 


\section{Conflicts of interest/Competing interests}

Not applicable' for that section.

\section{Availability of data and material}

The authors agree with Availability of data and material.

\section{Code availability}

The authors agree with Code availability.

\section{Authors' contributions}

Not applicable' for that section.

\section{Ethics approval}

This study was carried out in accordance with ethical principles in animal experimentation, approved by the Ethics Committee on the Use of Animals at the Federal University of Rio Grande do Sul under protocol number 29966/2016 of CEUA / UFRGS.

\section{Consent to participate}

All authors effectively participated in this research.

\section{Consent for publication}

All authors of this research agree with the publication of the article in Tropical Animal Health and Production.

\section{References}

1. Alvåsen, K., Mörk, M.J., Sandgren, C.H., Thomsen, P.T., Emanuelson, U., 2012. Herd-level risk factors associated with cow mortality in Swedish dairy herds. Journal of dairy science, 95(8), 4352-4362.

2. Andersson, B.E. and Jónasson, H., 1993.Temperature Regulation and Environmental Physiology, Dukes' Physiology of Domestic Animals, 11Ed, 886-895.

3. Astessiano, A.L., Meikle, A., Fajardo, M., Gil, J., Mattiauda, D.A., Chilibroste, P., Carriquiry, M. 2015. Metabolic and endocrine profiles and hepatic gene expression of Holstein cows fed total mixed ration or pasture with different grazing strategies during early lactation. Acta Veterinaria Scandinavica, 57(1), 1-12.

4. Bell, A. W., 1995. Regulation of organic nutrient metabolism during transition from late pregnancy to early lactation. Journal of animal science, 73(9), 2804-2819. 
5. Bendixen, P.H., Vilson, B., Ekesbo, I., Åstrand, D.B., 1986. Disease frequencies of tied zero-grazing dairy cows and of dairy cows on pasture during summer and tied during winter. Preventive veterinary medicine, 4(4), 291-306.

6. Benzaquen, M.E., Risco, C.A., Archbald, L.F., Melendez, P., Thatcher, M.J.,Thatcher, W.W., 2007. Rectal temperature, calving-related factors, and the incidence of puerperal metritis in postpartum dairy cows. Journal of dairy science, 90(6), 2804-2814.

7. Bond, G.B., Almeida, R.D., Ostrensky, A., Molento, C.F.M., 2012. Métodos de diagnóstico e pontos críticos de bem-estar de bovinos leiteiros. Ciência Rural, 42(7), 1286-1293.

8. Boulton, A.C., Rushton, J., Wathes, D.C., 2017. An empirical analysis of the cost of rearing dairy heifers from birth to first calving and the time taken to repay these costs. Animal, 11(8), 1372-1380.

9. Butler, W.R., 2000. Nutritional interactions with reproductive performance in dairy cattle. Animal reproduction science, 60, 449-457.

10. Chilibroste, P., Soca, P., Mattiauda, D.A., Bentancur, O., Robinson, P.H., 2007. Short term fasting as a tool to design effective grazing strategies for lactating dairy cattle: a review. Australian Journal of Experimental Agriculture, 47(9), 1075-1084.

11. Drillich, M., Beetz, O., Pfützner, A., Sabin, M., Sabin, H.J., Kutzer, P., Heuwieser, W., 2001. Evaluation of a systemic antibiotic treatment of toxic puerperal metritis in dairy cows. Journal of Dairy Science, 84(9), 2010-2017.

12. Duffield, T. (2000). Subclinical ketosis in lactating dairy cattle. Veterinary clinics of north america: Food animal practice, 16(2), 231-253.

13. Edmonson, A.J., Lean, I.J., Weaver, L.D., Farver, T., Webster, G., 1989. A body condition scoring chart for Holstein dairy cows. Journal of dairy science, 72(1), 68-78.

14. Giuliodori, M.J., Delavaud, C., Chilliard, Y., Becú-Villalobos, D., Lacau-Mengido, I., de la Sota, R.L.. 2011. High NEFA concentrations around parturition are associated with delayed ovulations in grazing dairy cows. Livestock Science, 141(2-3), 123-128.

15. Guretzky, N.J., Carlson, D.B., Garrett, J.E., Drackley, J.K., 2006. Lipid metabolite profiles and milk production for Holstein and Jersey cows fed rumen-protected choline during the periparturient period. Journal of dairy science, 89(1), 188-200.

16. Gustafson, G.M., 1993. Effects of daily exercise on the health of tied dairy cows. Preventive veterinary medicine, 17(3-4), 209-223.

17. Horst, R.L., Goff, J.P., Reinhardt, T.A., Buxton, D.R., 1997. Strategies for preventing milk fever in dairy cattle. Journal of dairy Science, 80(7), 1269-1280.

18. Ingvartsen, K.L., Moyes, K.M., 2015. Factors contributing to immunosuppression in the dairy cow during the periparturient period. Japanese Journal of Veterinary Research, 63(S1), 15-24.

19. Koch, G.M.D.S., 2013. Incidência e consequências da hipocalcémia subclínica no pós-parto de vacas leiteiras (unpublished PhD thesis, University of Lisboa). 
20. Kristula, M., Smith, B., Simeone, A., 2001. The use of daily postpartum rectal temperatures to select dairy cows for treatment with systemic antibiotics. The Bovine Practitioner, 35(2), 117-125.

21. LeBlanc, S.J., Lissemore, K.D., Kelton, D.F., Duffield, T.F., Leslie, K.E., 2006. Major advances in disease prevention in dairy cattle. Journal of Dairy Science, 89(4), 1267-1279.

22. Leme, T.M.S.P., Pires, M.F.Á, Verneque, R.S., Alvim, M.J. Aroeira, L.J.M., 2005. Comportamento de vacas mestiças Holandês $x$ Zebu, em pastagem de Brachiaria decumbens em sistema silvipastoril. Ciência e Agrotecnologia, 29(3), 668-675.

23. Madoz, L.V., Giuliodori, M.J., Jaureguiberry, M., Plöntzke, J., Drillich, M., de la Sota, R.L., 2013. The relationship between endometrial cytology during estrous cycle and cutoff points for the diagnosis of subclinical endometritis in grazing dairy cows. Journal of dairy science, 96(7), 4333-4339.

24. Mee, J.F., 2004. Managing the dairy cow at calving time. Veterinary Clinics: Food Animal Practice, 20(3), 521-546.

25. Nascimento, G.V., Cardoso, E.D.A., Batista, N.L., de Souza, B.B., Cambuí, G.B., 2013. Indicadores produtivos, fisiológicos e comportamentais de vacas de leite. Agropecuária Cientifica no semiárido, 9(4), 28-36.

26. O'Hara, L.A., Båge, R., Holtenius, K., 2016. The impact of body condition after calving on metabolism and milk progesterone profiles in two breeds of dairy cows. Acta Veterinaria Scandinavica, 58(1), 9194.

27. Overton, T.R., Waldron, M.R., 2004. Nutritional management of transition dairy cows: strategies to optimize metabolic health. Journal of dairy science, 87, 105-119.

28. Popescu, S., Borda, C., Diugan, E.A., Spinu, M., Groza, I.S., Sandru, C.D., 2013. Dairy cows welfare quality in tie-stall housing system with or without access to exercise. Acta Veterinaria Scandinavica, 55(1), 1-11.

29. Sheldon, I.M., Rycroft, A.N., Zhou, C., 2004. Association between postpartum pyrexia and uterine bacterial infection in dairy cattle. Veterinary Record, 154(10), 289-293.

30. Sheldon, I.M., Lewis, G.S., LeBlanc, S., Gilbert, R.O., 2006. Defining postpartum uterine disease in cattle. Theriogenology, 65(8), 1516-1530.

31. Suthar, V., Burfeind, O., Bonk, S., Voigtsberger, R., Keane, C., Heuwieser, W., 2012. Factors associated with body temperature of healthy Holstein dairy cows during the first 10 days in milk. Journal of Dairy Research, London, 79(2), 135-142.

32. Van den Top, A.M., Van Tol, A., Jansen, H., Geelen, M.J., Beynen, A.C., 2005. Fatty liver in dairy cows post partum is associated with decreased concentration of plasma triacylglycerols and decreased activity of lipoprotein lipase in adipocytes. The Journal of dairy research, 72(2), 129-137.

33. Vogel, K.D., Claus, J.R., Grandin, T., Oetzel, G.R., Schaefer, D.M., 2011. Effect of water and feed withdrawal and health status on blood and serum components, body weight loss, and meat and carcass characteristics of Holstein slaughter cows. Journal of animal science, 89(2), 538-548.

\section{Figures}




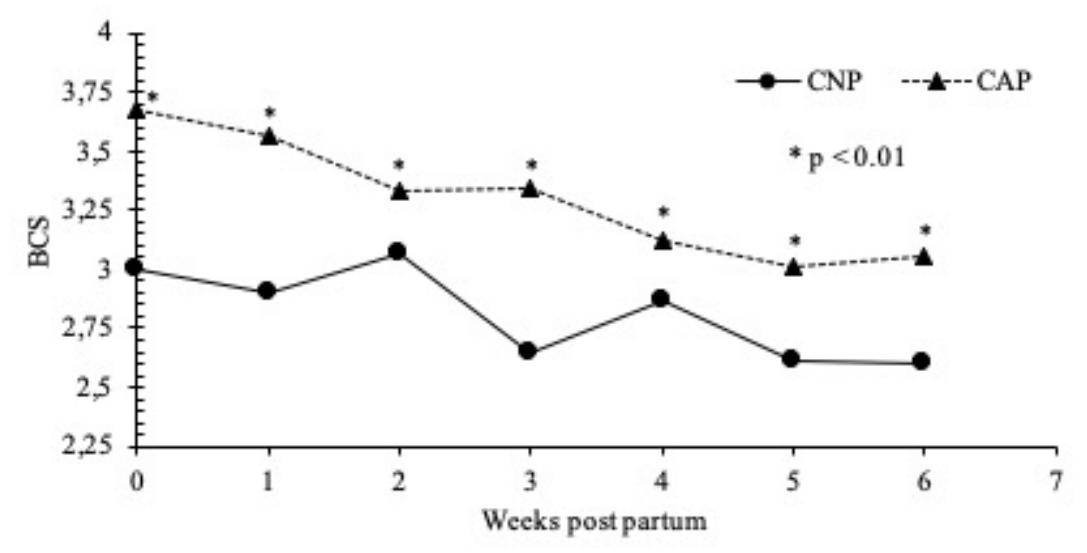

Figure 1

Comparison of mean body condition scores (BCS) in Holstein cows housed in farms in the mountains of Rio Grande do Sul, Brazil, from calving until six weeks postpartum, in animals from either confinement production systems (CNP) or confinement with access to pasture (CAP)

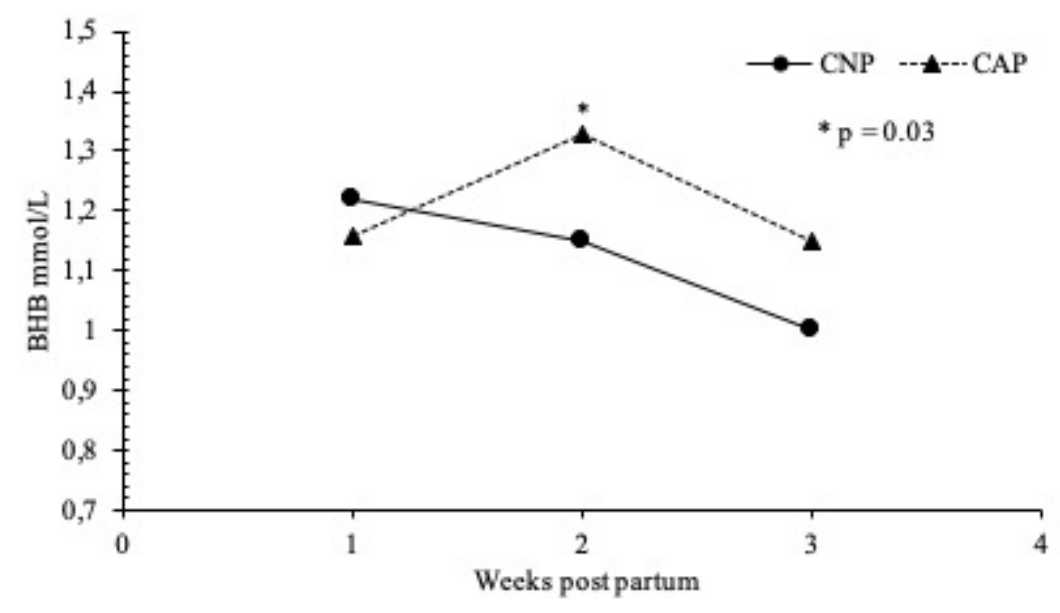

Figure 2

Comparison of averages of beta-hydroxybutyrate concentration (BHB) in the serum in Holstein cows housed in farms in the mountains of Rio Grande do Sul, Brazil, in the three weeks postpartum in animals from either confinement production systems (CNP) or confinement with access to pasture (CAP)

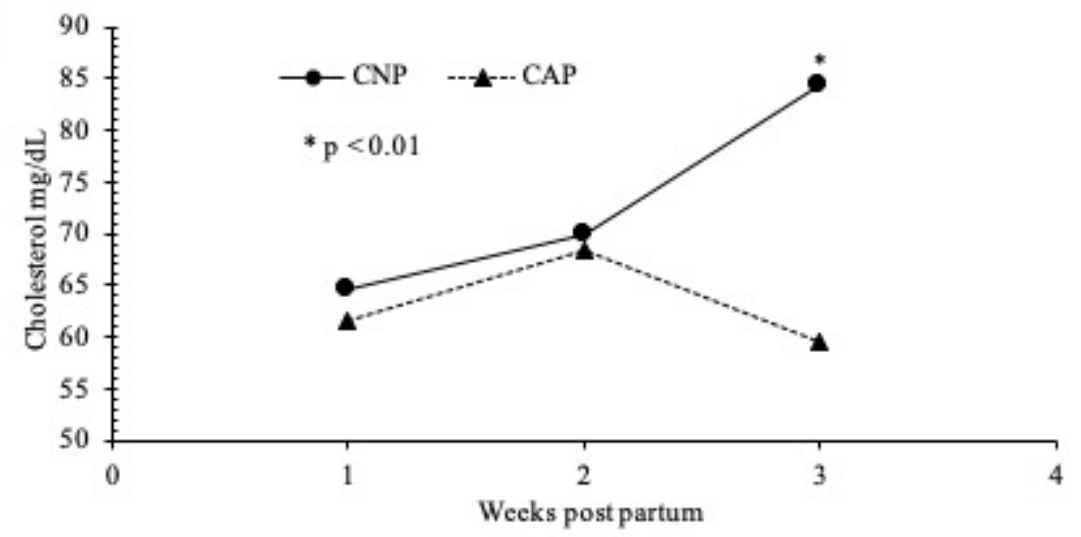




\section{Figure 3}

Comparison of mean serum cholesterol concentrations in Holstein cows housed in farms in the mountains of Rio Grande do Sul, Brazil, in the three weeks postpartum, in animals from either confinement production systems (CNP) or confinement with access to pasture (CAP)

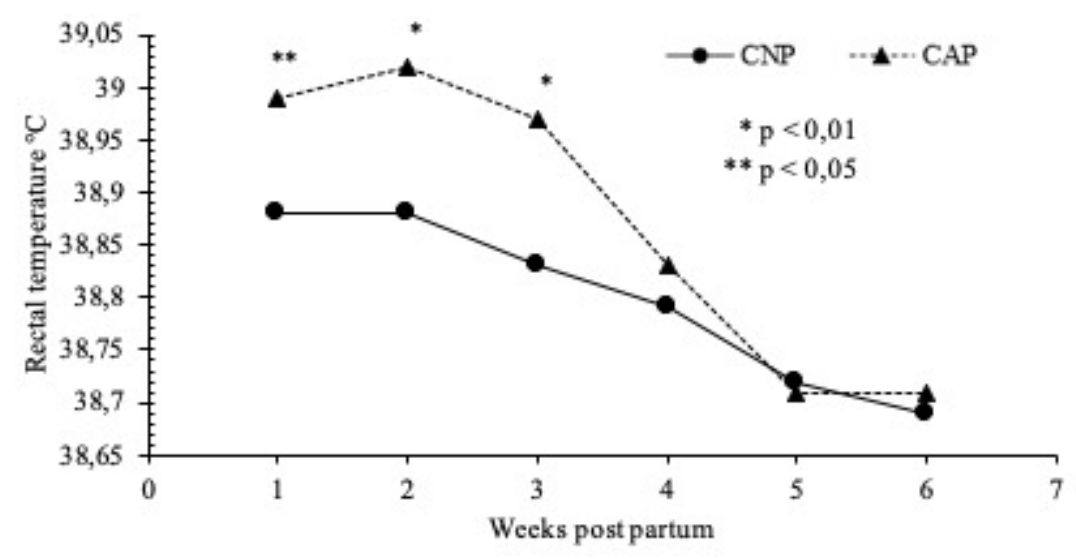

\section{Figure 4}

Differences between average rectal temperatures in Holstein cows housed in farms in the mountain range of Rio Grande do Sul, Brazil, in the six weeks postpartum, in animals from either confinement production systems (CNP) or confinement with access to pasture (CAP)

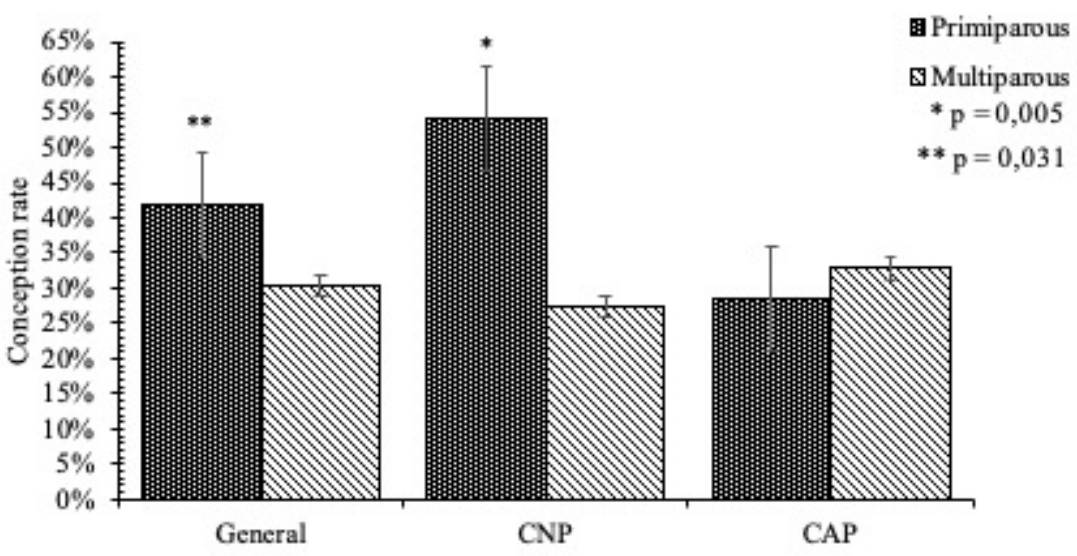

Figure 5

Comparison of conception rates and parities of Holstein cows, where general indicates the overall average of all cows in this study, CAP indicates values for animals from confinement production systems, and CAP indicates animals in confinement systems with access to pasture (CAP), in Serra do Rio Grande do South, Brazil 